\title{
Evaluation of Drug Use at Four Hospitals in Khartoum, Sudan
}

\section{Abbas $\mathbf{O}^{1}$, Saeed $\mathrm{AA}^{2}$, Hassan $\mathrm{TM}^{1}$ and Mousnad MA ${ }^{3 *}$}

${ }^{1}$ Hospital pharmacy, National University, Sudan

${ }^{2}$ Department of pharmacology and therapeutics, pharmacy program, Napata CollegeKhartoum, Sudan

${ }^{3}$ Department of Pharmacy Practice, International University of Africa (IUA), Khartoum, Sudan

\section{Research Article \\ Volume 3 Issue 1}

Received Date: January 16, 2020

Published Date: February 10, 2020

DOI: $10.23880 /$ jqhe- 16000150

*Corresponding author: Mohamed Mousnad, Consultant of Pharmacoeconomics \& Pharmacoepidemiology, Assistant Professor, Faculty of Pharmacy, International University of Africa (IUA), Khartoum, Sudan, Email: m_abdalaziz@yahoo.com

\section{Abstract}

Background: Drug use is a complex subject involving the prescriber, the dispenser, the patient and pharmaceutical institutions. Inappropriate drug use is the problem of the whole world; however, the degree of the problem is higher in developing countries like Sudan.

Objective: The present study was carried out to assess the pattern of drug use by using World Health Organization's Patient Care indicator in Selected Health Facilities in Khartoum state.

Method: A descriptive, quantitative and cross-sectional study was conducted among hospital outpatients. The sample was selected using systematic random sampling. In each hospital, patient care indicators were investigated through collection of data on 268 patient encounters, determination of consultation time and dispensing time for 268 patients, and by interview of 268 patients for the evaluation of dispensing practices.

Results: The mean consultation time was found to be 13.93 minutes, whereas the mean dispensing time was found to be 122.78 seconds, the total number of drugs prescribed was 1080 , and the percentage of medications actually dispensed in the hospitals was calculated to be $58.98 \%$, percentage of drug adequately labelled was $8.96 \%$, Patients who knew their dosage forms accurately were found, 180 patients.

Conclusion: The result of the resent study indicates that the patient consulting time, medications, labeling and availability of key drugs in the hospitals are inadequate. These patient care indicators need special attention for improvement. Professionals of all levels of health care, management and leaders should be trained in quality issues. Essential drug supply management systems should be established to ensure availability of key drugs in the outpatient pharmacies of the hospitals.

Keywords: Evaluation of Drug; Health Care System; Drug

\section{Introduction}

Medicines are essential components of a health care system and play a crucial role in saving people's life. Essential medicines are selected to satisfy the real need of population in diagnostic, prophylactic, therapeutic purposes [1]. Increasing access to and ensuring appropriate use of essential medicines could improve health status and secure development gains [2]. Drug use evaluation is a system of ongoing, systematic, criteria-based assessment that ensures the appropriate use of drugs [3].

WHO core drug use indicators include: Prescribing indicators, patient care indicators and facility indicators.

Patient care indicators address key aspects of what patients' experience at health facilities, and how well they have been prepared to deal with the pharmaceuticals that 
have been prescribed and dispensed and they serve as a simple method of monitoring drug use in a standardized way [4].

Patient consulting and dispensing times have the purpose of measuring the time that both medical personnel and dispensing personnel spend with patients in the process of consulting, prescribing and dispensing drugs. The time that prescribers and dispensers spend with each patient may indicate the potential quality of diagnosis and treatment [59].

Irrational drug uses are common in both developed and developing countries, the degree of the problem is higher in developing countries like Ethiopia where practices such as polypharmacy, the use of wrong or ineffective drugs, underuse or incorrect use of effective drugs and overuse of antimicrobials and injections are widespread [10]. Moreover, in developing countries, Sudan in particular, there are many medication safety issues and inappropriate practice habits at the health facilities. As the consequent this study was carried out to assess the Patterns of Drug Use by using World Health Organization's Patient Care indicator in Selected Health Facilities in Khartoum state and the effectiveness of the information given to patients on the dosage schedule of the drugs they receive.

\section{Methodology}

\section{Study Design}

A cross-sectional study for WHO patient care indicator was conducted on patients who visited the outpatient departments of four hospitals.

\section{Study Area}

This study was conducted at four hospitals in Khartoum state (Ibrahim Malik, Soba teaching hospital, Best Care, Royal Care).

\section{Study Period}

This study was performed during the period from December 2018 to January 2019.

\section{Study Population} above.

Patients who received any medication and age of 18 and

\section{Exclusion Criteria}

Patients who did not receive any medication, below the age of 18 and those who were not on ease to respond interview were excluded from this study.

\section{Ethical Considerations}

The interview was carried out only with full consent of the patient/caregiver interviewed. Each respondent was assured that the information provided by him/ her would be confidential and used only for the purpose of research.

\section{Sample Size}

The calculation was carried out based on the following assumption. The assumptions: Level of confidence $95 \%, 5$ $\%$ margin of error and $\mathrm{P}$ is the proportion of patients who visited the hospitals and took correct patient care. The actual sample size for the study was computed.

Two hundred sixty-eight patients were selected by systematic rand om sampling in the four hospitals to minimize bias which can be made due to difference in patient load on different days in a week and variation in pattern of hospital visits for chronic care patients.

\section{Data Collection}

Consultation and dispensing times were recorded by observation of actual contact with physicians and pharmacists. The number of drugs dispensed against the number of drugs prescribed per encounter was recorded in pharmacy at the point of prescription filling. For medication labeling and patient knowledge about dispensed medicines, packages were observed, and patients were interviewed on exiting the pharmacy.

The data collection was carried out primarily by the outpatient pharmacists, adequate labeling of dispensed drugs and patient knowledge about the dispensed drugs were assessed according to $\mathrm{WHO}$ data collection format for patient care indicator (additional format).

\section{Data Analysis}

The data generated for each hospital were entered into a computer using Statistical Package for the Social Sciences (SPSS) version 20.0 software to be edited, cleaned, and analyzed. The data were analyzed descriptively and summarized using tables and a bar chart. The findings were compared and contrasted with other national and international studies.

The mean and percentage value of indicator variables were calculated in this study using the following formula:

Mean consultation time $=$ sum of all consultation times $/$ total number of patients consulted. 
Mean dispensing time $=$ sum of all dispensing times $/$ total number of samples.

Percentage of drugs dispensed = number of drugs dispensed/ number of drugs prescribed x 100.

Percentage of drugs adequately labelled $=$ drugs labelled adequately/drugs prescribed x 100 .

Percentage of patients aware of the correct dosage $=$ patients with the correct knowledge of the dosage of all drugs dispensed/patients interviewed x 100 .

\section{Results}

All participants were interviewed, and the summary of patient care indicators included mean consultation time, mean dispensing time, percentage of drug adequately labelled and percentage of drugs dispensed in Table 1.

\begin{tabular}{|c|c|}
\hline Patient care indicators & $\begin{array}{c}\text { In Khartoum state } \\
\text { four hospitals }\end{array}$ \\
\hline $\begin{array}{c}\text { mean consultation time (in } \\
\text { minutes) }\end{array}$ & 13.93 \\
\hline Mean dispensing time (in seconds) & 122.78 \\
\hline Percentage of drugs dispensed & $58.98 \%$ \\
\hline $\begin{array}{c}\text { Percentage of drugs adequately } \\
\text { labelled }\end{array}$ & $8.96 \%$ \\
\hline
\end{tabular}

Table 1: Summary of patient care indicators in four hospitals at Khartoum state December 2018.

\begin{tabular}{|c|c|}
\hline Medications & Percentage (\%) \\
\hline Adequately labelled & 8.96 \\
\hline Inadequately labelled & 91.04 \\
\hline
\end{tabular}

Table 2: Total number of drugs adequately labelled.

\begin{tabular}{|c|c|c|}
\hline Missed labeling data & N & Percentage (\%) \\
\hline Frequency of dosing & 32 & 13.11 \\
\hline Duration & 40 & 16.39 \\
\hline Side effects & 222 & 90.98 \\
\hline Precautions & 225 & 92.21 \\
\hline
\end{tabular}

Table 3: Drugs inadequately labelled were differentiated according to the missed data from the label information, and the percentages were represented.

Frequency of dosing was not written in $13.11 \%$ of the medications dispensed, the duration of treatment was not included in the label information in $16.39 \%$ of the total number of the medication, side effects and precautions was not included in the label information in more than $90 \%$ of the total number of prescription of the patients have been interviewed (Figures $1 \& 2$ ).
Information to be told by the dispenser to the patients are:

1. The name of the drug dispensed

2. The dose of the drug dispensed

3. Duration of the treatment

4. Frequency of administration

5. Possible side effects.

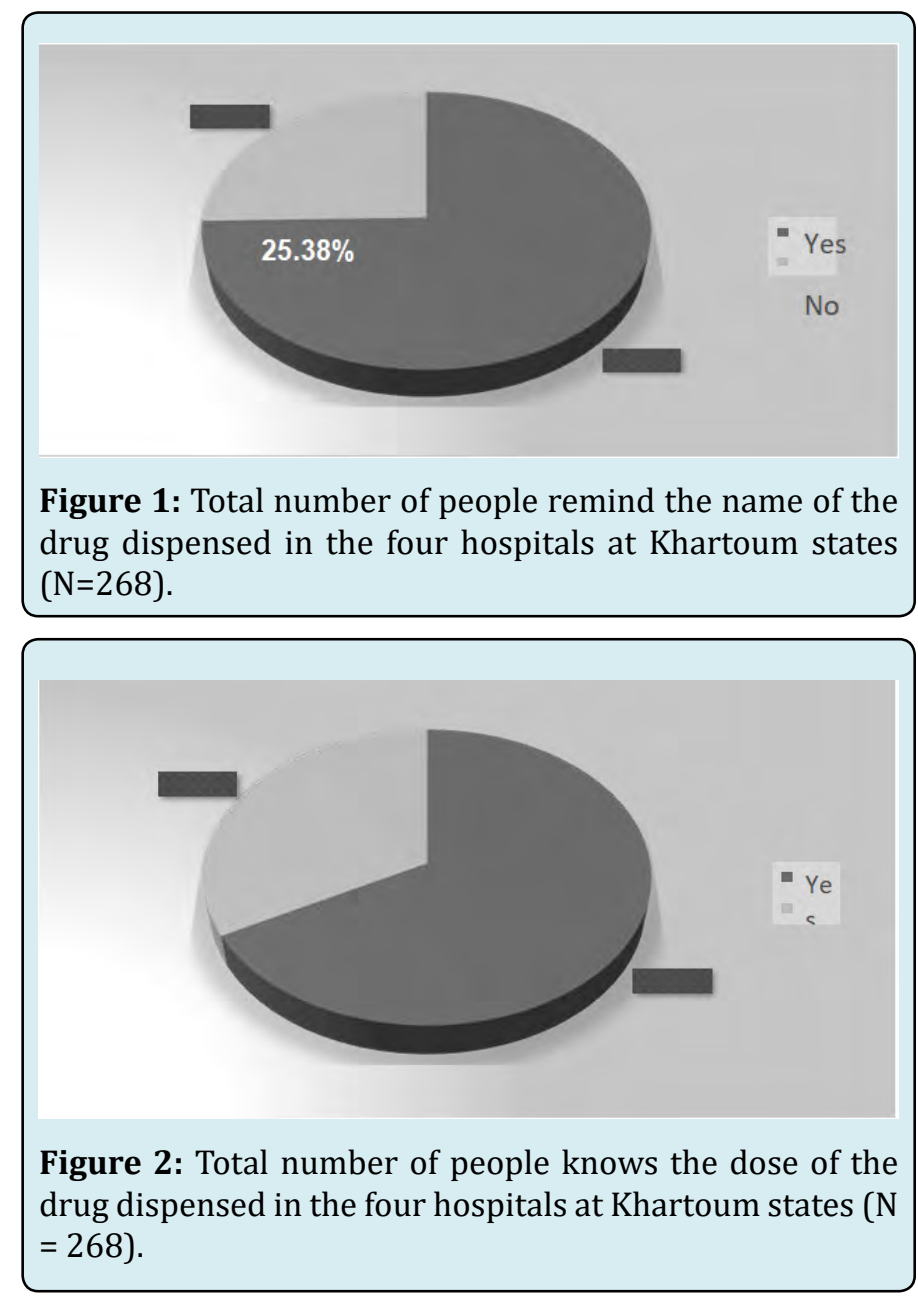

\begin{tabular}{|c|c|}
\hline Patients & Percentage (\%) \\
\hline Knew & 78.35 \\
\hline Did not & 21.65 \\
\hline
\end{tabular}

Table 4: Total number of patients knew the duration of the treatment in four hospitals at Khartoum states $(\mathrm{N}=268)$.

\begin{tabular}{|c|c|}
\hline Patients & Percentage (\%) \\
\hline Knew & 82.08 \\
\hline Did not & 17.92 \\
\hline
\end{tabular}

Table 5: Total number of people know the frequency of administration in four hospitals at Khartoum states $(\mathrm{N}=$ 268). 


\begin{tabular}{|c|c|}
\hline Patients & Percentage (\%) \\
\hline Knew & 22.38 \\
\hline Did not & 77.62 \\
\hline
\end{tabular}

Table 6: Total number of people know the possible side effect of the drug dispensed in four hospitals at Khartoum states $(\mathrm{N}=268)$

\section{Discussion}

The patient care indicators were developed by WHO to measure the mean consultation time, mean dispensing time, percentage of adequately labelled drug, percentage of drugs dispensed and the patient knowledge about the drug dispensed.

The physician should proceed with a full evaluation to the patient case at the time the patient enters the consultation room, and he should have left with the appropriate medication selected for him through a proper patient-physician interaction.

The mean consultation time of this study was found to be 13.93 minutes; this was longer than what was reported in North West Ethiopia, Jordan and India which were 3.9 and 4 min respectively $[11,12]$.

Mean consulting time in studies in six European countries was $10.7 \mathrm{~min}$, and in the United Arab Emirates it was $10 \min [13]$.

Times reported in this current study, as well as in the studies reviewed, were well below the optimal consultation time of $\geq 30 \mathrm{~min}$ recommended for conducting proper history taking, complete physical examination, appropriate health education instructions and prescribing therapy [14]. The current study showed that the consultation time is too short to enable physicians to communicate with their patients regarding their therapy and illness.

The average consultation times reported from other developing countries are even lower, ranging from 2.8-7 min [15-18].

The average dispensing time reported in this study (122.78 s) was longer than the optimal dispensing time of $\geq$ $60 \mathrm{~s}$. This average time was also longer than that reported in studies conducted at PHC facilities in Jordan (28.8 s) and in Kuwait (54.6 s) [19,20].

This average time was also longer than that reported in studies conducted at PHC facilities in Jordan (28.8 s) and in Kuwait (54.6 s) [15,20]. Dispensing time $<60 \mathrm{~s}$ is insufficient by WHO criteria to explain the dosage regimen, adverse effects of drugs, all precautions and label and dispense a drug. Patient compliance directly depends on his/her knowledge about the drug and therefore an adequate dispensing time is a necessary step towards improving patient care [21].

The percentage of prescribed drugs dispensed was low (58.98) comparing to the percentage of drugs dispensed in Kuwait which was $97 \%$ [15]. An inadequate drug supply has implications for patients' health status which is inconvenient for patients and jeopardises their trust in the health system [21]. WHO recommends that each drug label should contain the dose regimen, patient name and drug dose, in this study drug labelling practice was very poor, only $8.96 \%$, compared with an optimal value of $100 \%$ which can be attributed to the lack of a labelling system where dispensary personnel only write the frequency of administration of each drug on the pillbox or medicines bag. The poor labelling reported in this study is comparable with the results of the study in Kuwait where $66.9 \%$ were adequately labelled [22-25].

Patient's knowledge of the correct dosage is highly beneficial to avoid drug overuse and abuse and prevent adverse effects that harm patients' health status, which was low in this study.

Another study showed average consultation and dispensing time in facilities 3.82 minute and 3.66 minutes, respectively. The probable reason for such smaller time could be a large number of patient flow for which the doctors and pharmacy professionals urged to cover, and the smaller number of human resources. The findings from this study were smaller than the study conducted in South West of Ethiopia 6.14 minute and 1.28 minute respectively [22].

In this study, none of labels for the drugs dispensed was adequately done, according to WHO a label to be adequate it should contain at least patient name, drug name, strength, dosage (dose and frequency) and duration/quantity of the drug. However findings from similar studies showed that practice of adequate labelling was $67 \%[14,24,25]$. It could be explained by high patient flow, and inadequacy of knowledge and skill in labelling of prescribed drugs could be the major factors for these low results.

Percentage of drugs dispensed in this study was 484 $(45.7 \%)$ and $628(53.9 \%)$ respectively. This is lower than similar studies conducted in North West Ethiopia and different other countries like Nigeria and Colombia. It could be directly related to inadequate availability of essential drugs. Studies showed that good drug and medical supply management ensures a continuous supply of drugs and prevents frequent stock-outs and wastages [14,25-27]. 


\section{Conclusion}

The result of the resent study indicates that the patient consulting time, medications, labeling and availability of key drugs in the hospitals are inadequate. The medication labeling practice in the four hospitals is unacceptability low. These patient care indicators need special attention for improvement. Professionals of all levels of health care, management and leaders should be trained in quality issues. Essential drug supply management systems should be established to ensure availability of key drugs in the outpatient pharmacies of the hospitals. We recommend that consultation times need to be longer and reasons for the short times need to be investigated. Drug labeling systems need to be improved to include drug regimen, patient name and drug dose, and the availability of key drugs stocks needs to be improved. Health care providers, professionals, financiers and also decision-makers (politicians) should be involved in the development and the selection of the quality indicators.

\section{References}

1. Hogerzeil HV (1995) Promoting rational prescribing: an international perspective. British Journal of Clinical Pharmacology 39(1): 1-6.

2. Habib SS, Perveen S, Khuwaja HMA (2016) The role of micro health insurance in providing financial risk protection in developing countries- a systematic review. BMC Public Health 16: 281.

3. Sisay M, Mengistu G, Molla B, Amare F, Gabriel T (2017) Evaluation of rational drug use based on World Health Organization core drug use indicators in selected public hospitals of eastern Ethiopia: a cross sectional study, BMC Health Services Research 17(1): 161.

4. Ndukwe HC, Ikoni J, Sariem CN (2013) Drugs use pattern with standard indicators in jos university teaching hospital Nigeria. West African journal of pharmacy 24(1): 88-93.

5. Haque M (2017) Essential Medicine Utilization and Situation in Selected Ten Developing Countries: A Compendious Audit. Journal of International Society of Preventive and Community Dentistry 7(4): 147-160.

6. Boonstra E, Lindbaek M, Ngome E (2003) Labelling and patient knowledge of dispensed drugs as quality indicators in primary care in Botswana. BMJ Quality \& Safety 12: 168-175.

7. Remy Pacifique Ntirenganya (2018) Assessment of Patient Care Indicators in Three District Hospitals in Rural Rwanda: A Cross-Sectional Study. IOSR Journal of
Pharmacy 8(7): 36-39.

8. Jurgutis A, Vainiomaki P, Stasy R (2011) Primary Health Care Quality indicators for a more Sustainable Health Care System In Lithuania, Management theory and studies for rural business and infrastructure development 2(26): 76-86.

9. Gidebo KD, Summoro TS, Kanche ZZ, Woticha EW (2016) Assessment of drug use patterns in terms of the WHO patient-care and facility indicators at four hospitals in Southern Ethiopia: A cross sectional study. BMC Health Services Research 16: 643.

10. Ofori Asenso R, Agyeman AA (2016) Irrational Use of Medicines-A Summary of Key Concepts. Pharmacy (Basel) 4(4): 35.

11. Mende M, Tadesse T, Ayele A (2017) Assessment of Drug use Pattern by Using WHO Core Drug use Indicators at Public Hospitals in Ethiopia. International Journal of case studies in clinical research 1(6): 114-122.

12. Atif M, Sarwar MR, Azaam M, Naz M, Amir S, et al. (2016) Assessment of core drug use indicators using WHO/ INRUD methodology at primary healthcare centers in Bahawalpur, Pakistan. BMC Health Services Research 16(1): 684.

13. Deveugele M, Derese A, Brink Muinen A, Bensing J, Maeseneer JD (2002) Consultation length in general practice: cross sectional study in Six European countries. British Medical Journal 325(7362): 472.

14. El Mahalli AA, Akl OAM, Al-Dawood SF, Al-Nehab AA, AlKubaish HA, et al. (2012) WHO/INRUD patient care and facility- specific drug use indicators at primary health care centers in Eastern province, Saudi Arabia. Eastern Mediterranean Health Journal 18(11): 1086-1090.

15. Awad A, Al-Saffar N (2010) Evaluation of drug use practices at primary healthcare centers of Kuwait. Eur J Clin Pharmacol 66(12): 1247-1255.

16. Angamo MT, Wabe NT, Raju NJ (2011) Assessment of Patterns of Drug use by using World Health Organization's Prescribing, Patient Care and Health facility indicators in Selected Health Facilities in Southwest Ethiopia. Journal of applied Pharmceutical Science 1(07): 62-66.

17. Gopalakrishnan S, Ajitha K, Ganeshkumar P, Selvaraj I, Logaraj M (2012) Assessment of patient care and health facility indicators among urban and rural private practitioners in Kancheepuram district of Tamil Nadu, India. National Journal of Research in Community Medicine 1(4): 178-241. 
18. Bannenberg WJ (1991) Evaluation of the Nile province essential drugs project, mission report by a WHO team, Sudan, 27 April - 12 May 1991 Wilbert J. Bannenberg, World Health Organization.

19. Atif M, Rehan M (2016) Assessment of core drug use indicators using WHO/INRUD methodology at primary healthcare centers in Bahawalpur, Pakistan. BMC Health Serv Res 16: 684 .

20. Otoom S, Batieha A, Hadidi H, Hasan M, Al-Saudi K (2002) Evaluation of drug use in Jordan using WHO patient care and health facility indicators. Eastern Mediterranean Health Journal 8(4-5): 544-549.

21. (2002) Promoting Rational Use of Medicines: Core Components - WHO Policy Perspectives on Medicines, No. 005, September 2002, Geneva, USA.

22. Odusanya $O 0$ (2004) Drug use indicators at a secondary health care facility in Lagos, Nigeria. Journal of Community Medicine \& Primary Health Care 16(1): 2124.
23. Guyon AB, Barman AA, Ahmed JU, Ahmed AU, AIam MS (1994) A baseline survey on use of drugs at the primary health care level in Bangladesh. Bull world Health Organ 72(2): 265-271.

24. (1998) Management Sciences for Health, Managing Drug Supply, West Hartford, Connecticut, USA: Kumarian Press 25-26.

25. Lamichhane DC, Giri B, Pathak O, Panta O, Shankar P (2006) Morbidity profile and prescribing patterns among outpatients in a teaching hospital in western Nepal. Mcgill Journal of Medicine 9(2): 126-133.

26. Acurcio FA, Perini E, Magalhaes SM, Terceiro LG, Vieira Filho JM, et al. (2004) Analysis of medical prescriptions dispensed at health centers in Belo Horizonte, Minas Gerais, Brazil. Cad SaudePublica 20: 72-79.

27. Neighbour R (2004) The inner consultation: How to Develop an Effective and Intuitive Consulting Style. $2^{\text {nd }}$ (Edn.), Radcliffe Medical Press. 